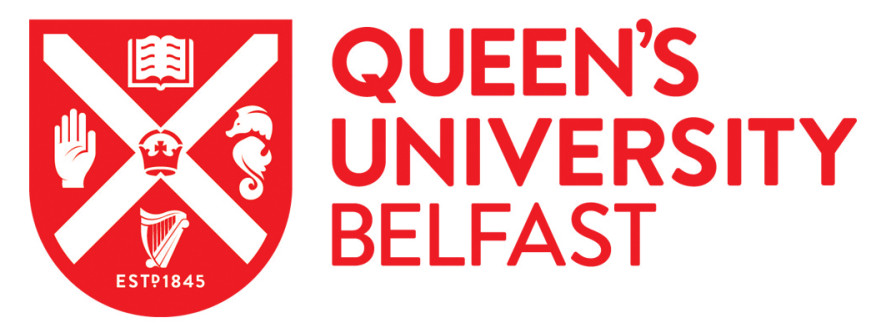

\title{
Applications of lonic Liquids in Gas Processing
}

Ng, S., Atilhan, M., Karadas, F., Jacquemin, J., Thompson, J., Rooney, D., \& Khraisheh, M. (2012). Applications of lonic Liquids in Gas Processing. 133-138. Paper presented at 3rd Gas Processing Symposium, Doha, Qatar. https://doi.org/10.1016/B978-0-444-59496-9.50021-7

\section{Document Version:}

Early version, also known as pre-print

Queen's University Belfast - Research Portal:

Link to publication record in Queen's University Belfast Research Portal

\section{General rights}

Copyright for the publications made accessible via the Queen's University Belfast Research Portal is retained by the author(s) and / or other copyright owners and it is a condition of accessing these publications that users recognise and abide by the legal requirements associated with these rights.

Take down policy

The Research Portal is Queen's institutional repository that provides access to Queen's research output. Every effort has been made to ensure that content in the Research Portal does not infringe any person's rights, or applicable UK laws. If you discover content in the Research Portal that you believe breaches copyright or violates any law, please contact openaccess@qub.ac.uk. 
Abdelwahab Aroussi and Farid Benyahia (Editors), Proceedings of the 3rd International Gas

Processing Symposium, March 5 - 72012 , Qatar.

(C) 2012 Elsevier B.V. All rights reserved.

\title{
Applications of Ionic Liquids in Gas Processing
}

\author{
Shieling Ng ${ }^{\mathrm{a}, \mathrm{b}}$, Mert Atilhan ${ }^{\mathrm{a}}$, Ferdi Karadas ${ }^{\mathrm{a}}$, Johan Jacquemin ${ }^{\mathrm{b}}$, Jillian \\ Thompson ${ }^{\mathrm{b}}$, David Rooney ${ }^{\mathrm{b}}$,Majeda Khraisheh ${ }^{\mathrm{a}}$. \\ ${ }^{a}$ Qatar University, P.O. Box 2713, Doha, Qatar \\ ${ }^{b}$ Queen's University Ionic Liquid Laboratory (QUILL), David Keir Building, Stranmillis \\ Road, Belfast BT9 5AG, Northern Ireland, UK.
}

\begin{abstract}
Over the last decade ionic liquids have grown from relatively poorly understood materials to become integrated into industrial applications. These materials are, quite simply, comprised entirely of ions, and are liquid at room temperature. Given their nature, they have been described as "designer" solvents, with "tuneable" features that can be adjusted to suit the requirements of a particular process. A huge interest in using ionic liquids as an alternative medium for gas separation has become apparent because of such properties. For example, the high thermal stability of ionic liquids provide considerable potential to utilize them for $\mathrm{CO}_{2}$ capture application. This paper investigates the potential of ionic liquids in gas processing applications. Initial screenings of the ability of ionic liquids for $\mathrm{CO}_{2}$ separation up to 100 bar are presented.
\end{abstract}

Keywords: ionic liquid, $\mathrm{CO}_{2}$ absorption, high pressure.

\section{Introduction}

During the last decade, ionic liquids have been transformed from poorly understood materials to the focus of many research activities, both in academic research and industrial applications ${ }^{1}$. A huge interest in using ionic liquids as an alternative medium for $\mathrm{CO}_{2}$ capture has become apparent because of its potential advantages compared to other conventional solvents, such as MEA ${ }^{2}$. There are many ways in which an ionic liquid can be defined, and perhaps the most widely accepted definition is, "A material that is composed solely of ions" . Ionic liquids are a very versatile class of solvents, due to their unique characteristics, such as the ability to manipulate and tune their physicochemical properties through cation or anion selection ${ }^{3}$, non-volatility under ambient conditions, high thermal stability, as well as high $\mathrm{CO}_{2}$ solubility, may overcome many of the problems associated with current $\mathrm{CO}_{2}$-removal techniques ${ }^{4}$. It is also very important to note that ionic liquids are not solutions of ions in water, or other solvents.

Aqueous amine scrubbing (MEA, MDEA) is currently the most used technology for $\mathrm{CO}_{2}$ capture. However, $\mathrm{CO}_{2}$ capture using MEA, for example, would result in a $28 \%$ energy loss, and therefore double the cost of electricity usage, due to the heat required to regenerate used aqueous MEA solutions ${ }^{5}$. Ionic liquids offer the possibility of reducing the energy demand for $\mathrm{CO}_{2}$ stripping during solvent regeneration by as much as $16 \%$ relative to aqueous MEA solutions ${ }^{6}$.

${ }^{1}$ Corresponding author: Email: m.khraisheh@qu.edu.qa 
The high thermal stability of ionic liquids provides considerable potential to utilize ionic liquids for $\mathrm{CO}_{2}$ capture applications. Most ionic liquids are stable to over $300{ }^{\circ} \mathrm{C}$ and therefore less likely to degrade via oxidation, to react with impurities or to be corrosive ${ }^{7}$. And because ionic liquids have negligible vapor pressure, this creates a possibility of ionic liquids regeneration over a wide range of temperatures and pressures. Thus, this offers a new opportunity for process optimization that is not achievable using traditional aqueous liquid capture media.

One of the biggest drawbacks to the large scale use of ionic liquids in $\mathrm{CO}_{2}$ capture is their higher cost compared to the conventional solvents they are proposed to replace ${ }^{8}$. However, "by reducing or eliminating process losses through thermal degradation, oxidative or chemical destruction and vapor loss, the amount of solvent needed for the process may be greatly reduced" ". In addition, ionic liquids are synthesized at Qatar University from commercially available, cheap starting materials in order to reduce the cost of ionic liquids production. These will all help to counterbalance the apparent economic disadvantage of the ionic liquids, especially in industrial applications.

\section{Methodology}

\subsection{Synthesis of Ionic Liquids}

1-Bromoethane $\left(55.0 \mathrm{~cm}^{3} ; 0.505 \mathrm{~mol}\right.$; b. pt. $\left.38.4^{\circ} \mathrm{C}\right)$ and toluene $\left(20.0 \mathrm{~cm}^{3}\right)$ were added drop wise to 1 -methylimidazole $\left(41.0 \mathrm{~cm}^{3} ; 0.499 \mathrm{~mol}\right)$ in a round-bottomed flask equipped with a stirring bar. The reaction mixture was stir-heated at $60{ }^{\circ} \mathrm{C}$ under a reflux condenser and maintained at this temperature for $3 \mathrm{~h}$ with stirring. A biphasic mixture was formed with a light yellow color in the upper layer and a slightly darker yellow in the lower layer. The mixture was transferred to a separating funnel where the bottom layer, which contained $\left[\mathrm{C}_{2} \mathrm{mim}\right] \mathrm{Br}$ and an excess of 1-bromoethane, was collected into another round-bottomed flask. The separated lower layer was then washed with hexane $\left(3 \times 50 \mathrm{~cm}^{3}\right)$ in order to remove the excess of unreacted 1-bromoethane from the product before the hexane was removed under vacuum. The remaining viscous yellow liquid was then dried in vacuo at $80^{\circ} \mathrm{C}$ for $15 \mathrm{~h}$, at which point it solidified to yield a yellowish solid.

The bromide ionic liquid was dissolved in distilled water $\left(200 \mathrm{~cm}^{3}\right)$, and then transferred into a conical flask $\left(500 \mathrm{~cm}^{3}\right)$ equipped with a stirring bar. A slight excess of lithium bistriflamide was weighed $(57.56 \mathrm{~g} ; 0.201 \mathrm{~mol})$ in a beaker, dissolved in distilled water $\left(100 \mathrm{~cm}^{3}\right)$, and then poured into the conical flask. The mixture was left to stir for $2 \mathrm{~h}$ at room temperature. A biphasic layer was formed, with a clear upper layer (aqueous layer) and yellow bottom layer (bistriflamide ionic liquid) respectively. The upper layer was decanted, and the bottom yellow layer was then transferred to a separating funnel. It was then washed with water $\left(4 \mathrm{x} 100 \mathrm{~cm}^{3}\right)$. The bottom yellow layer was collected from the separating funnel and was left to dry for $15 \mathrm{~h}$ under high vacuum at $80{ }^{\circ} \mathrm{C}$ to remove any traces of water. The product was obtained as a yellow liquid.

These procedures were then repeated for the synthesis of $\left[\mathrm{C}_{4} \mathrm{mim}\right]\left[\mathrm{NTf}_{2}\right]$ by replacing 1-bromoethane with 1-bromobutane, in the alkylation reaction with 1-methylimidazole.

\section{2. $\mathrm{CO}_{2}$ Solubility Measurements}

Both ionic liquids synthesised with be tested for their ability for $\mathrm{CO}_{2}$ absorption up to 100 bar, as descibed in details by Karadas et al. 9. Measurements were performed using the high-pressure magnetic suspension balance (MSB) sorption device by Rubotherm 
Präzisionsmesstechnik $\mathrm{GmbH}$ apparatus.This equipment is specially designed to measure sample mass change with high precision upon $\mathrm{CO}_{2}$ absorption under high pressure and raised temperature.The $\mathrm{CO}_{2}$ absorption in $\left[\mathrm{C}_{2} \mathrm{mim}\right]\left[\mathrm{NTf}_{2}\right]$ and $\left[\mathrm{C}_{4} \mathrm{mim}\right]\left[\mathrm{NTf}_{2}\right]$ were performed at both $46{ }^{\circ} \mathrm{C}$ and $66{ }^{\circ} \mathrm{C}$, in order to mimicked the well-head temperature here in Qatar. The results are shown in Figure 4.

\section{Results and Discussion}

The large demand for ionic liquids has resulted in further development of their synthetic protocols, allowing large scale production of ionic liquids which are of consistently high purity while minimizing time and cost. With so many combinations of ionic liquids, it is very hard to generalize one synthetic protocol that is applicable for the synthesis of all ionic liquids. The synthetic routes used to prepare ionic liquids are varied. Here, the most popular and straight-forward way for the syntheses of $\left[\mathrm{C}_{2} \mathrm{mim}\right]\left[\mathrm{NTf}_{2}\right]$ and $\left[\mathrm{C}_{4} \mathrm{mim}\right]\left[\mathrm{NTf}_{2}\right]$ via alkylation were opted, as depicted in Figure 1. This synthetic protocol can be carried out using any alkylating agent (i.e. 1-bromoalkane) to yield bromide ionic liquids. These bromide ionic liquids then undergo an anion-exchange reaction with lithium bistriflamide, to yield the desired bistriflamide ionic liquids. This reaction is very well-known, clean and efficient reaction for the preparation of any bistriflamide ionic liquids ${ }^{3,10}$.

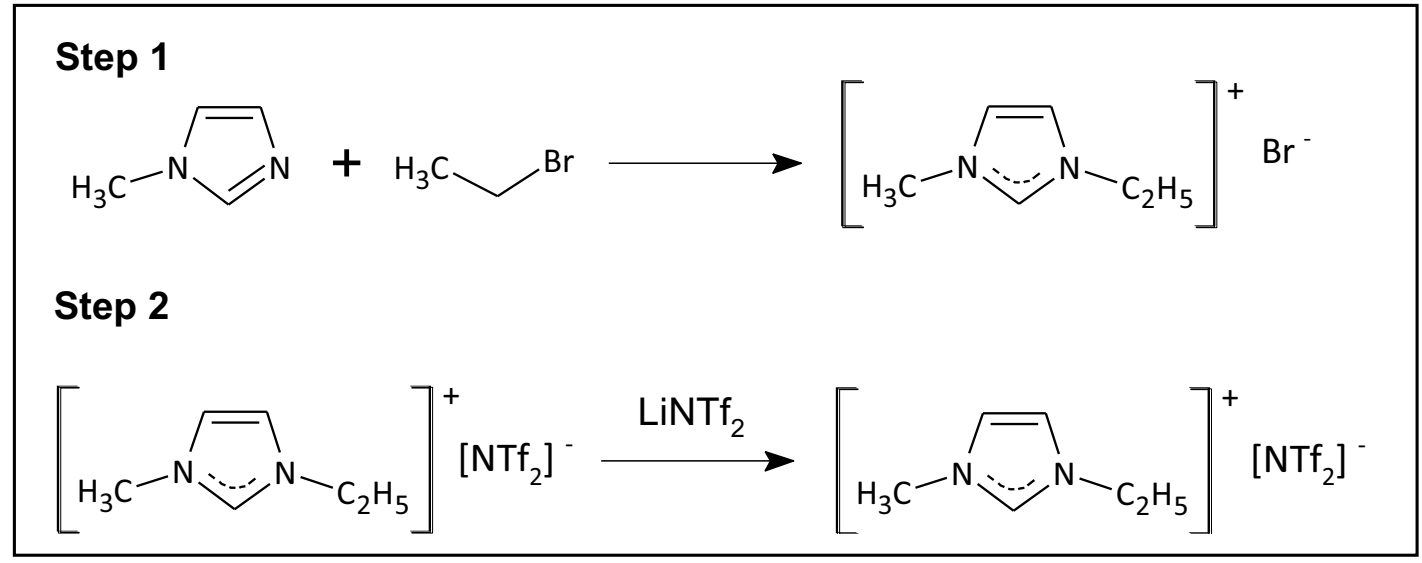

Figure 1: Two-step synthetic protocol for the preparation of bistriflamide ionic liquids.

Imidazolium ionic liquids are known to be a remarkable solvent for $\mathrm{CO}_{2}$ solubility ref. It has been found that anion play the important role in determining the gas solubility in ionic liquids. It has been reported that the bistriflamide anion has the greatest affinity for $\mathrm{CO}_{2}$ experimentally ${ }^{11}$, compared to other anions, such as the halides, triflate $\left([\mathrm{OTf}]^{-}\right)$, hexafluorophosphate $\left(\left[\mathrm{PF}_{6}\right]^{-}\right)$, tetrafluoroborate $\left(\left[\mathrm{BF}_{4}\right]^{-}\right)$, dicyanamide $\left(\left[\mathrm{N}(\mathrm{CN})_{2}\right]^{-}\right)$and ethanoate $\left(\left[\mathrm{MeCO}_{2}\right]^{-}\right){ }^{1}$. Although fluorination effect are shown to have greatly enhanced the solubility of $\mathrm{CO}_{2}$, these class of ionic liquids are very expensive and are not environmental friendly, due its high stability and low reactivity ${ }^{12}$.

Although the anion is the key factor in determining the physical dissolution of $\mathrm{CO}_{2}$ in ionic liquids, the cation also plays a role. Despite a wide range of cations reported for $\mathrm{CO}_{2}$ capture, many research groups have concentrated on imidazolium cation. This is because of the acidic $\mathrm{C} 2$ proton from the imidazolium ring can interact with anion 
(especially carboxylate anion), to form an unstable carbene, which then coupled with $\mathrm{CO}_{2}$ molecules, resulting the removal of $\mathrm{CO}_{2}{ }^{13}$ (Figure 2).

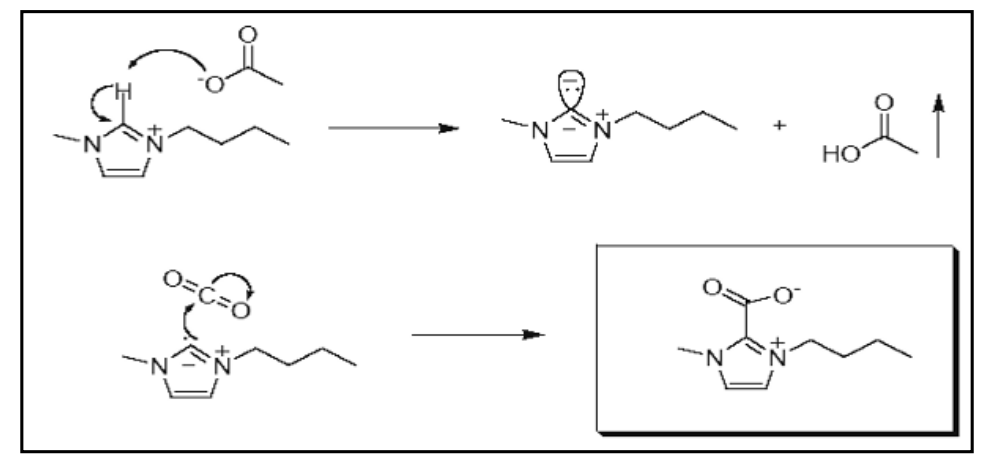

Figure 2: Proposed mechanism for enhanced $\mathrm{CO}_{2}$ solubility in imidazolium-based ionic liquids ${ }^{13}$.

Based on these literature reviews, we have decided to perform a simple screening of $\mathrm{CO}_{2}$ solubility in imidazolium bistriflamide ionic liquids. Two different alkyl chain length on imidazolium were chosen; 1-ethyl-3-methylimidazolium bistriflamide, $\left[\mathrm{C}_{2} \mathrm{mim}\right]\left[\mathrm{NTf}_{2}\right]$ and 1-butyl-3-methylimidazolium bistriflamide, $\left[\mathrm{C}_{4} \mathrm{mim}\right]\left[\mathrm{NTf}_{2}\right]$. Their chemical structures were shown in Figure 3.

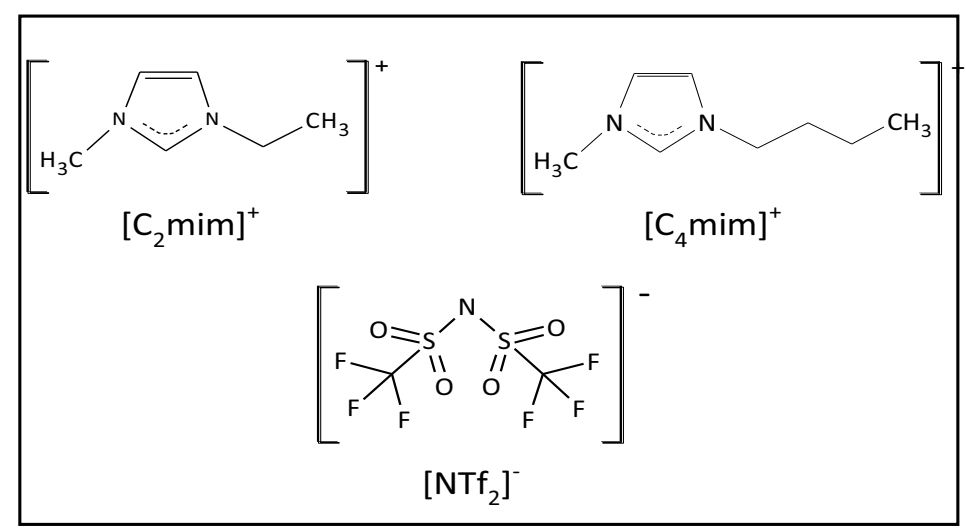

Figure 3: Chemical structure for $\left[\mathrm{C}_{2} \mathrm{mim}\right]\left[\mathrm{NTf}_{2}\right]$ and $\left[\mathrm{C}_{4} \mathrm{mim}\right]\left[\mathrm{NTf}_{2}\right]$.

The preliminary screening on the ability of these two ionic liquids to absorb $\mathrm{CO}_{2}$ showed very promising results, at pressure up to 100 bar, as shown in Figure 4. It is also shown that $\mathrm{CO}_{2}$ solubility are indeed better in $\left[\mathrm{C}_{4} \mathrm{mim}\right]\left[\mathrm{NTf}_{2}\right]$ than in $\left[\mathrm{C}_{2} \mathrm{mim}\right]\left[\mathrm{NTf}_{2}\right]$ at both $46{ }^{\circ} \mathrm{C}$ and $66{ }^{\circ} \mathrm{C}$, as described in the literature. This might be associated with a "free volume" mechanism, where a gas molecule can arrange itself into the free volume of ionic liquids ${ }^{14}$.

However, more screening of different classes of ionic liquids, with different combinations of cations and anionsarescheduled in order to identify the best system for $\mathrm{CO}_{2}$ capture in Qatar. Besides, the effects of water content, as well as higher pressure $\mathrm{CO}_{2}$ measurements (up to 200 bar) are also proposed to be studied. It is also very important to note that the $\mathrm{CO}_{2}$ solubility measurement in ionic liquids at such high pressure has never been published. This will be the starting point and will be crucial for high pressure $\mathrm{CO}_{2}$ absorption research in the near future. 


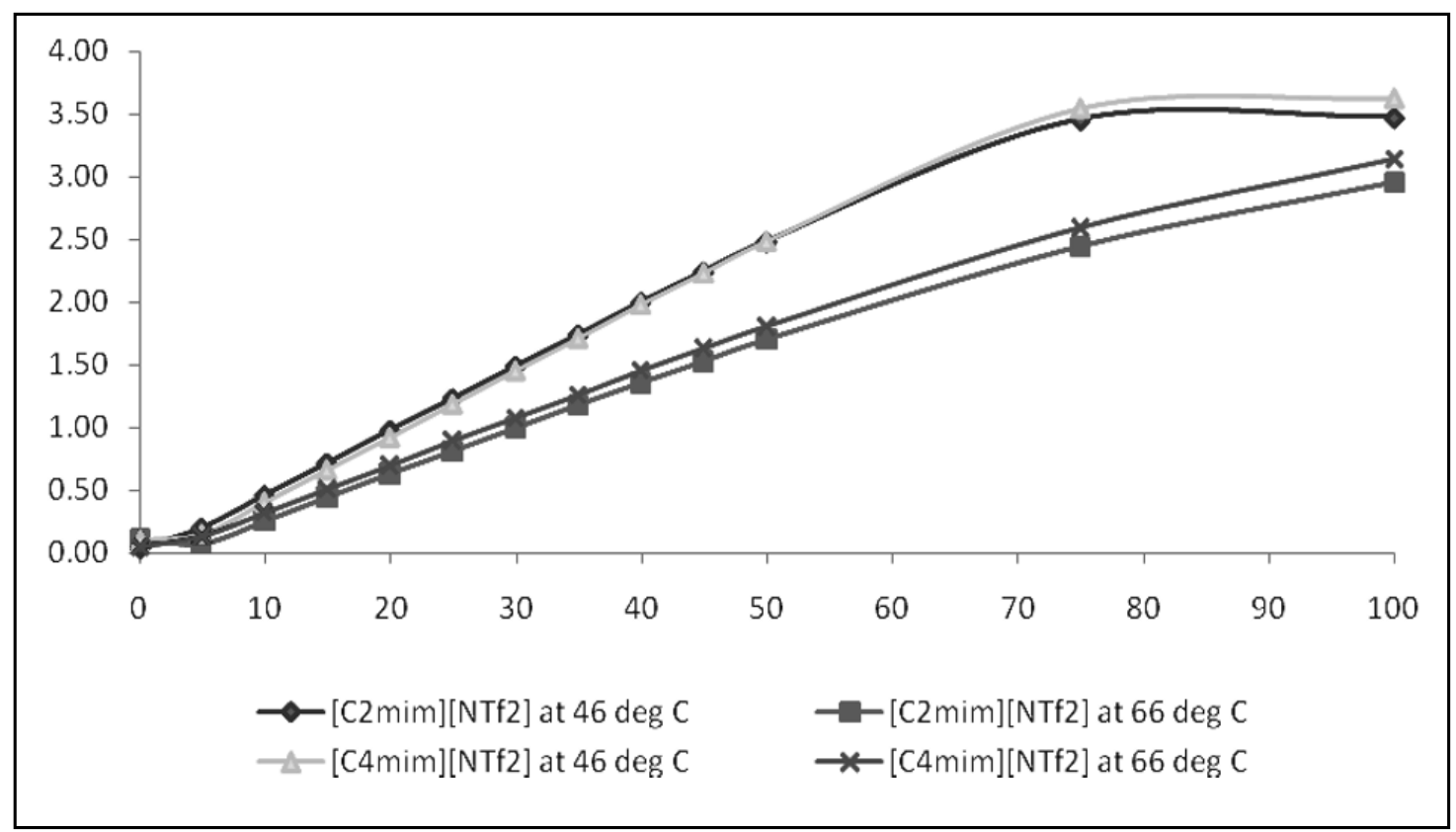

Figure 4: $\mathrm{CO}_{2}$ solubility measurements in both $\left[\mathrm{C}_{2} \mathrm{mim}\right]\left[\mathrm{NTf}_{2}\right]$ and $\left[\mathrm{C}_{4} \mathrm{mim}\right]\left[\mathrm{NTf}_{2}\right]$ at $46^{\circ} \mathrm{C}$ and $66^{\circ} \mathrm{C}$.

\section{Summary}

The use of ionic liquids for industrial application is proven to be possible, despite their reputation of being very expensive. Synthesis of ionic liquids using cheap materials can indeed lower the total operation cost for its application in $\mathrm{CO}_{2}$ capture in Qatar's oil and gas industry. Preliminary results of $\mathrm{CO}_{2}$ absorption using $\left[\mathrm{C}_{2} \mathrm{mim}\right]\left[\mathrm{NTf}_{2}\right]$ and $\left[\mathrm{C}_{4} \mathrm{mim}\right]\left[\mathrm{NTf}_{2}\right]$ showed that ionic liquid are very promising in replacing the conventional technology for $\mathrm{CO}_{2}$ removal, at both $46{ }^{\circ} \mathrm{C}$ and $66{ }^{\circ} \mathrm{C}$, at high pressure (100 bar) . However, more intensive studies have to be performed in order to introduce this future state-of-the-art technology using ionic liquid in the industry.

\section{Acknowledgement}

This publication was made possible by a grant from the Qatar National Research Fund under its National Priorities Research Program award number NPRP-09-739-2-284. Its contents are solely the responsibility of the authors and do not necessarily represent the official views of the Qatar National Research Fund.

\section{References}

(1) MacDowell, N.; Florin, N.; Buchard, A.; Hallett, J.; Galindo, A.; Jackson, G.; Adjiman, C. S.; Williams, C. K.; Shah, N.; Fennell, P. Energy Environ. Sci. 2010, 3, 1645.

(2) Hasib-ur-Rahman, M.; Siaj, M.; Larachi, F. Chem. Eng. Process. 2010, 49, 313.

(3) Gordon, C. M.; Muldoon, M. J.; Wagner, M.; Hilgers, C.; Davis Jr, J. H.; Wasserscheid, P. In Ionic liquids in synthesis; $2^{\text {nd }}$ ed.; Wassercheid, P., Welton, T., Eds.; Wiley-VCH Verlags GmbH \& Co. KGaA: Weinheim, 2008; Vol. 1. 
(4) Maginn, E. J. "Design and evaluation of ionic liquids as novel $\mathrm{CO}_{2}$ absorbents Quarterly technical report to DOE," University of Notre Dame, 2005.

(5) Gurkan, B. E.; Fuente, J. C. d. 1.; Mindrup, E. M.; Ficke, L. E.; Goodrich, B. F.; Price, E. A.; Schneider, W. F.; Maginn, E.; Brennecke, J. F. Clearwater Clean Coal Conference, Clearwater, Florida, 2010; $\mathrm{p} 1$.

(6) Wappel, D.; Gronald, G.; Kalb, R.; Draxler, J. Int. J. Greenhouse Gas Control 2009, 4, 486.

(7) Forsyth, S. A.; Pringle, J. M.; MacFarlane, D. R. Aust. J. Chem. 2004, 57, 113.

(8) Huang, J.; Rüther, T. Aust. J. Chem. 2009, 62, 298.

(9) Karadas, F.; Yavuz, C. T.; Zulfiqar, S.; Aparicio, S.; Stucky, G. D.; Atilhan, M. Langmuir 2011, 27, 10642.

(10) (a) Freemantle, M. Introduction to ionic liquids; Royal Society of Chemistry: Cambridge, 2010(b) Brégeon, D.; Levillain, J.; Guillen, F.; Plaquevent, J.-C.; Gaumont, A.-C. In Ionic Liquids in Organic Synthesis; ACS Symposium Series: Washington D.C., 2007; Vol. 950.

(11) Cadena, C.; Anthony, J. L.; Shah, J. K.; Morrow, T. I.; Brennecke, J. F.; Maginn, E. J. J. Am. Chem. Soc. 2004, 126, 5300.

(12) (a) Beckman, E. J. Chem. Commun. 2004, 1885(b) Adams, D. E. C.; Halden, R. U. In Contaminants of emerging concern in the environment: Ecological and human health considerations; Halden, R. U., Ed.; ACS Symposium Series: Washington D.C., 2010; Vol. 1048.

(13) Arduengo(III), A. J. Acc. Chem. Res. 1999, 32, 913.

(14) Kilaru, P. K.; Scovazzo, P. Ind. Eng. Chem. Res. 2008, 47, 910. 